\title{
International Journal for the Scholarship of
} Teaching and Learning

Volume 13 | Number 3

Article 6

November 2019

\section{Shedding Light on Student Learning Through the Use of Lightboard Videos}

\author{
Peter D. Rogers \\ Georgia Southern University, progers@georgiasouthern.edu \\ Diana T. Botnaru \\ Georgia Southern University, dbotnaru@georgiasouthern.edu
}

Follow this and additional works at: https://digitalcommons.georgiasouthern.edu/ij-sotl

\section{Recommended Citation}

Rogers, Peter D. and Botnaru, Diana T. (2019) "Shedding Light on Student Learning Through the Use of Lightboard Videos," International Journal for the Scholarship of Teaching and Learning: Vol. 13: No. 3, Article 6.

Available at: https://doi.org/10.20429/ijsotl.2019.130306 


\title{
Shedding Light on Student Learning Through the Use of Lightboard Videos
}

\begin{abstract}
This mixed-method study examined the effect of Lightboard videos on student learning and perceptions in a Flipped Classroom Model (FCM). The study targeted 68 civil engineering undergraduate students at a 4-year public university in Southeastern USA. Lightboard videos were intentionally alternated between two consecutive semesters. Within the same section of the course, classes without Lightboard videos served as a control group and classes with Lightboard videos served as a study group. Both sections were taught by the same instructor utilizing the same materials and assessments for the class. Student academic performance was measured using in-class assignments. Additional quantitative and qualitative data were collected through an end-of-semester survey. Data show a modest academic performance increase on the overall score on in-class assignments and an improvement of average student scores on $69.2 \%$ of the in-class assignments in the study group. The overall means on the Likert scale survey showed a strong endorsement of Lightboard videos for understanding, engagement and satisfaction. Students commented positively on the collaborative aspect of in-class problem solving in FCM.
\end{abstract}

\section{Keywords}

Lightboard, inverted classroom, critical thinking, civil engineering

\section{Creative Commons License} cc) (i) $\odot$

This work is licensed under a Creative Commons Attribution-Noncommercial-No Derivative Works 4.0 License.

\section{Cover Page Footnote}

The Lightboard videos used for this project were developed through a collaborative effort between the University's Center for Online Learning (COL), Information Technology Services (ITS), Multimedia Development Center and the Department of Civil Engineering and Construction Management. Whereas the videos were recorded by the first author at the MDC with help from MDC staff, COL staff assisted with the pre-recording training and final video editing and publishing. The Lightboard unit was constructed by Jessica and Jeff Orvis, faculty members in the Chemistry Department at our University. This project was made possible through the SoTL Fellowship program sponsored by the university's Center for Excellence in Teaching. 
IJ-SoTL, Vol. 13 [2019], N0. 3, Art. 6

\title{
Shedding Light on Student Learning Through the Use of Lightboard Videos
}

\author{
Peter D. Rogers and Diana T. Botnaru \\ Georgia Southern University
}

Received 30 August 2018;Accepted 14 June 2019

\begin{abstract}
This mixed-method study examined the effect of Lightboard videos on student learning and perceptions in a Flipped Classroom Model (FCM). The study targeted 68 civil engineering undergraduate students at a 4-year public university in Southeastern USA. Lightboard videos were intentionally alternated between two consecutive semesters. Within the same section of the course, classes without Lightboard videos served as a control group and classes with Lightboard videos served as a study group. Both sections were taught by the same instructor utilizing the same materials and assessments for the class. Student academic performance was measured using in-class assignments. Additional quantitative and qualitative data were collected through an end-of-semester survey. Data show a modest academic performance increase on the overall score on in-class assignments and an improvement of average student scores on $69.2 \%$ of the in-class assignments in the study group. The overall means on the Likertscale survey showed a strong endorsement of Lightboard videos for understanding, engagement and satisfaction. Students commented positively on the collaborative aspect of in-class problem solving in FCM.
\end{abstract}

\section{INTRODUCTION}

\section{Flipped Classroom Model}

In a traditional classroom model (TCM), students are first exposed to a lesson through a classroom lecture. They then try to learn the content through activities after class. The Flipped Classroom Model (FCM) challenges this idea, shifting the first exposure to outside of class through a pre-class element (typically utilizing online sources) so that class time can be allocated for active-learning activities such as problem solving, computer software applications, and class discussions. This in turn leads to opportunities for students to engage in advanced concepts and collaborative learning (Tucker, 20I2). Flipped classrooms (also known as inverted classrooms) have been in existence for some time. There are numerous definitions for the flipped classroom ranging from Lage, Platt, and Treglia (2000) "events that traditionally taken place inside the classroom now take place outside and vice versa" (p.32) to "an educational technique that consists of two-parts: interactive group learning activities inside the classroom, and direct computer-based individual instruction outside the classroom" (Bishop \& Verleger, 2013, para. I5).” Bishop and Verleger (2013) and Strayer (2007) insist that to qualify as a flipped classroom, systematic use of technology in the course is necessary. Although recent literature differentiates between a flipped classroom and flipped learning (Chen ,Wang, \& Chen, 20I4), for the purpose of this manuscript, a flipped classroom is defined as "using time outside of class to read and view online lectures, while class time can be spent on hands-on learning, group discussion, and question/answers sessions" (Gerstein, 20I2, para 2).

The effects of FCM on student learning (as measured by academic performance) have been evaluated in many courses including: nursing (Missildine, Fountain, Summers, \& Gosselin, 20I3), statistics (Wilson, 20I3), human-computer interaction (Day \& Foley, 2006), biology (Moravec,Williams,Aguilar-Roca, \& O'Dowdal, 20I0), chemistry (Fitzgerald \& Li, 20I5) and basic pharmaceutics (McLaughlin et al., 20I4).When compared to a traditional lecture format, the FCM in these studies showed an increase in student academic performance on exams and/or assignments (Chen et al., 20I4;Tune, Sturek, \& Basile, 20I3). However, other studies did not find a significant difference in final grades between a FCM and a TCM (Lage et al., 20 I4; Johnson \& Renner, 2012; Strayer, 2007; Davies, Dean, \& Ball, 20I3).

Student perceptions have also yielded inconsistent results. Lage et al. (2000) identified that most students have a positive perception of the flipped model, although some students invariably disliked it and perceived the increased expectations for personal responsibility in learning as unfair or unreasonable (Wilson, 2013). Students reported experiencing more innovation and cooperation in a flipped classroom but were less satisfied with their preparation (Strayer, 2007), the web-based instruction (Frederickson, Reed, \& Clifford, 2005), and required more support and facilitation from the instructor (Kim, Kim, Khera, \& Getman, 20I4). The FCM had a positive impact on students' attitudes toward a class (Wilson, 2013), improved perceptions of the learning environment (Baepler,Walker, \& Driessen, 2014) and the perception that the flipped classroom greatly enhanced their learning (McLaughlin et al., 20 I4; Zappe, Leicht, Messner, \& Litzinger, 2009). Students also reported a more student-centered approach (Kim et al., 20l4) and increased engagement (Goodwin \& Miller, 20I3) in the flipped model. Conversely, Davies et al. (2013) showed no differences between flipped and traditional models in terms of student assessment of the value of class, how much was learned in class, willingness to recommend the class to others, or student evaluations of activities, although the mean scores/grades were more favorable in the flipped class.

\section{Use of Videos in FCM}

Multiple approaches can be used in FCM to present the information to students. They include video lectures using a whiteboard, narrated PowerPoints, YouTube videos, podcasts and readings. Many of the studies examining the effectiveness of videos in engineering courses only focused on studying student perceptions. In a study by Kao (2008), video podcasts (done through iTunes) were incorporated into several undergraduate and graduate level mechanical engineering courses with class sizes ranging from 20 to 60 students. Based on an analysis of 16 end-of-semester surveys, $90 \%$ of the students indicated that blending the courses with the podcasts was beneficial and students felt comfortable and empowered to learn with the technology. However, these findings should be treated with caution, given the small sample size. Halyo and 
Le (2013) reported on incorporating two video lectures into an Introduction to Engineering (freshmen level) and Introduction to Control Systems (senior level) courses. Students were asked to view each video prior to attending class to allow more time for instructor interaction and open-ended problem solving in-class. Students indicated that they preferred watching the videos to reading their textbooks, but no measures of student learning were collected. Similar projects outside the United States (Itani, 20I3) examined the use of videos as a learning tool in an engineering ethics course over a period of three semesters and collected students perceptions on: how well they understood the videos, the extent to which the videos helped relate to key concepts in the course, and opinions about the videos as a learning tool.While students viewed the videos an effective learning tool in engineering ethics courses and considered videos based on a true-story more effective in achieving the course outcomes than hypothetical ethics videos, the study did not assess student learning.

\section{Lightboard Technology}

Lightboard is an open source hardware, first developed by Michael Peshkin (Northwestern University). The Lightboard is a glass chalkboard pumped full of light. Unlike traditional whiteboards which require the lecturer to have his/her back to the camera during recording, the instructor faces the viewers, and the writing "glows" in front of the instructor. At our institution Lightboard has been used to record videos in multiple disciplines such as kinesiology, anatomy and physiology and chemistry (personal communication, 2018). A search on the use and evaluation of Lightboard on student learning revealed a paucity of information. In engineering, Lightboard had no effect on performance indicators for circuit problem skills, but a significant impact was found on outcome evaluation, diagrams and sketches, and neatness and organization. In addition, a survey indicated an increase in student self-confidence, but it was not significant. These results need to be interpreted with caution, because the sample size was small; only 17 students agreed to participate in the study and only seven completed the survey (Hite, Dawson, Ahern, Slimak, \& Korakasis, 2017).An article on the use of Lightboard in chemistry education discussed the advantages and disadvantages of the Lightboard, including the ease of creating the videos and their desirability due to the fact that the speaker faced the audience. However, it did not measure or report on student performance or perceptions of its use (Fung, 2017). Finally, a small pilot project in a nutrition course seem to indicate that Lightboard was engaging and led to a greater understanding of the material among students, but no information was available on sample size or instruments used (Smith \& Penumetcha, 20I7).

\section{Course Context}

The current study targeted Civil Engineering undergraduate students enrolled in a Fluid Mechanics course at a 4-year public university in Southeastern USA. Fluid Mechanics is a required course in the Civil Engineering curriculum usually taken during the second semester of the sophomore year.The course has both lecture and lab components and there are normally two sections of the course per semester. The content of the course can be seen in Table I.The purpose of the course is to teach students about the fundamental concepts of fluids (gases and liquids) in order to understand their behavior under varying loading and atmospheric conditions. Students in the course learn how to apply principles of continuity, energy, and momentum to understand the behavior of fluids at rest and in motion. Topics within the course include: hydrostatics, laminar and turbulent flows, fluid measurement, flow in conduits and channels, pumps, and turbines. These topics have numerous applications within the field of Civil Engineering and directly relate to the design, operation, and maintenance of critical infrastructure such as water distribution systems, treatment plants, dams, storm water collection systems, sanitary sewers and pumping stations.

There is some previous research indicating that engineers have a specific way of thinking. Lucas and Hanson (2016) developed six specific "engineering habits of mind' (EHoM) that included:

I. systems thinking - seeing whole, systems and parts, and how they connect, pattern-sniffing, recognizing interdependence, synthesizing

2. problem finding - clarifying needs, checking existing solutions, investigating contexts, verifying

3. visualizing - move from abstract to concrete, manipulating materials, mental rehearsal of physical space and of practical design solutions

4. improving - relentlessly trying to make things better by experimenting, designing, sketching, guessing, conjecturing, thought-experimenting, prototyping

5. creative problem solving - applying techniques from other traditions, generating ideas and solutions with others, generous but rigorous critiquing, seeing engineering a $s$ a "team sport"

6. adapting - testing analyzing, reflecting, re-thinking, changing (physically and mentally).

In addition to developing the EHoM, Lucas and Hanson (2016) advocated for the introduction of engineering teaching that develops these EHoM.These discipline-specific teaching practices are also known as signature pedagogies. Shulman (2005) defined signature pedagogy as "the types of teaching that organize the fundamental ways in which future practitioners are educated for their new profession" (p.52). We believe that the course in our study embodied several components of EHoM by creating a space for students to collaborate on problem-solving together during class, allowing them to generate ideas and solutions with other, as well as visualizing solutions presented on Lightboard videos (see class format below).

\section{Course Format and Organization}

\section{Before Class:}

Prior to attending class, students are required to review an online lesson which contains a combination of PowerPoint slides (providing terminology, fundamental concepts, derivations, etc.), internet-based videos illustrating real-life applications of the lesson topics, and Lightboard videos demonstrating example computations. Pre-class preparation in FCM is important for the quality of the in-class discussion. For this reason, students were required to print out, fill out, and turn in to the instructor at the beginning of the face-to-face class session a form called a "ticket." The "ticket" is a combination of short answer questions covering several key concepts and computational-based questions, which require students to rework examples covered within the online lesson (with different variables). In larger engineering classes, students' pre-class preparation is usually assessed by assigning quizzes. In this particular case, given the small class size, the instructor opted 
for an approach that allowed students to practice higher order thinking skills by solving problems based on the information in the online lesson.

In lieu of the importance of pre-class preparation in the FCM students entering the classroom without their completed "ticket' are considered absent for the class (which counts against their attendance grade accounting for 10\% of the final grade), but are allowed to participate in the problem solving portion of the class. As the "tickets" are collected, each was evaluated for completeness and originality (i.e. making sure that no two tickets are direct copies of each other). Students identified as having copied tickets were not given credit for attending that day's class. The "ticket" completion rates for the fall 2017 and spring 2018 semesters was $92.6 \%$ and $91.3 \%$ respectively.

\section{During Class:}

After tickets were collected, each class started with a I0-I5 minute lesson overview in which the instructor highlighted the concepts covered in the online lesson. In doing so, the instructor addressed the concepts addressed within the "ticket", while also emphasizing how the lesson's content related to previous and/or upcoming lessons, the course, and the profession. The remainder of the class time was devoted to in-class assignments that included problem solving sessions, computer-based activities with commonly-used software (MS Excel, Flow Master, etc.), and laboratory activities (formal and informal).

\section{Lightboard Video Addition}

The thirteen Lightboard videos used in the Fluid Mechanics course were developed over a period of two semesters at the University's Multimedia Development Center and integrated into the course in the 2017-2018 academic year. To evaluate the effects of Lightboard videos on student learning and perceptions, the following research questions were proposed:

\section{Are there differences in students' academ- ic performance between a FCM using Light- board videos and a FCM not using Lightboard videos (as measured by the average grades on in-class assignments)?}

2. What are student perceptions of engagement, satisfaction and understanding with Lightboard videos in a FCM?

\section{What are student perceptions about the FCM?}

\section{PARTICIPANTS}

Participants in this study included a total of 68 undergraduate Civil Engineering students enrolled in a Fluid Mechanics course over two semesters: 30 students in fall 2017 and 38 students in spring 2018.

\section{METHODOLOGY}

This was a mixed-method study carried out over the course of two semesters (fall 2017 and spring 2018). Lightboard videos were developed for every topic of the class (see Table I) prior to fall 2017. Lightboard technology was chosen over the whiteboard because it allowed the instructor to face the students without obstructing the board. The videos provided example computations, while emphasizing terminology. No superimposed images were provided.

The inclusion of the Lightboard videos within the course's online content followed a schedule that intentionally alternated between two consecutive semesters (see schedule in Table I).Whereas Lightboard videos were provided to students for lectures $3,5,7,9, I I$, and I 3 during the fall 2017 semester and no videos were provided for lectures $2,4,6,8,10,12$, and I4; students in the following spring 2018 semester were provided Lightboard videos for lectures $2,4,6,8,10,12$, and 14 , but no videos for lectures $3,5,7,9, I I$, and I 3 .Within the same section of the class, the lectures without Lightboard videos were used as a control group and the lectures with Lightboard videos were used as a study group. Both sections were taught by the same instructor utilizing the same materials and assessments for the class. No changes were made to Lightboard videos once the study started.

Student academic performance on identical in-class assignments was collected for comparison between the groups. The in-class assignments consisted of three or four quantitative problems that required students to understand and apply concepts presented through the online lecture. These assignments were completed during class and graded. Grades on in-class assignments were used as academic performance measures.

In addition to collecting data on academic performance, an anonymous student perception survey (see Appendix A) was administered at the end of the semester by the course teaching assistant. The survey was completed in class, was voluntary and no incentives were offered for completing it.

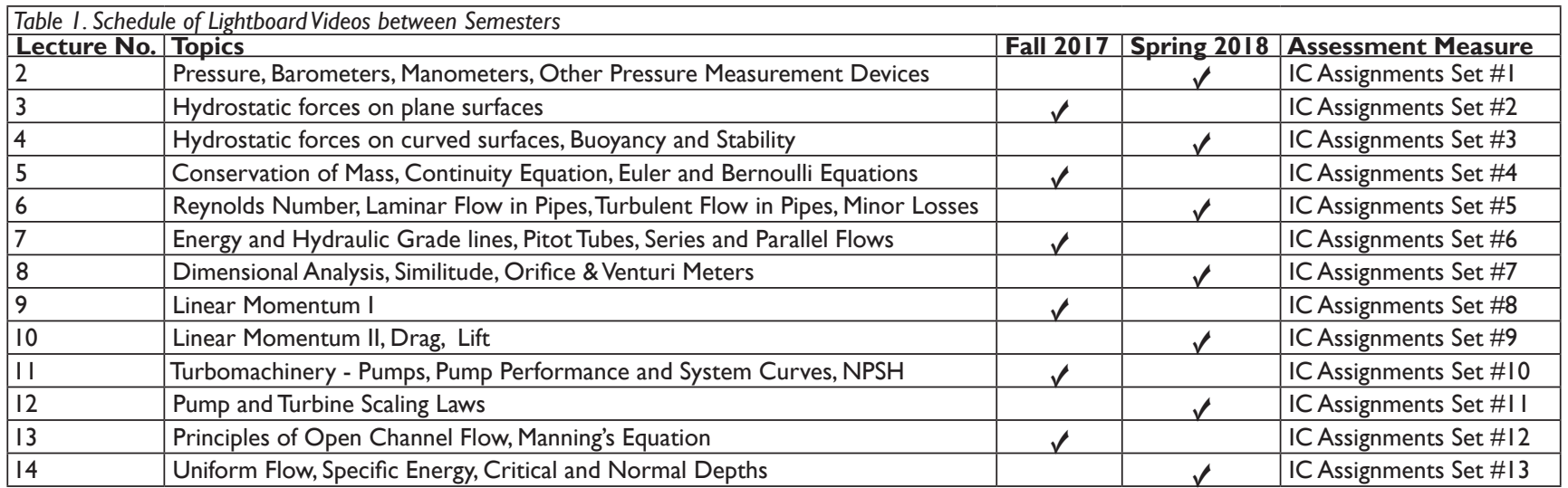


The survey consisted of 24 questions:

a. Two demographic questions on gender and self-reported GPA

b. Seventeen Likert-scale questions on student perceptions about the Lightboard videos. These questions were separated into three broad categories: understanding, engagement and satisfaction and adapted from a previously published survey (Sturges, Maurer, \& Cole 2009)

c. Five open-ended, short answer questions on student perceptions about the FCM.

\section{RESULTS \\ Quantitative Data Analyses}

\section{Academic Performance on In-Class assignments}

Table 2 compares student performance on same in-class assignments between the control group and the study group. The mean in-class assignment scores for the control group ranged from $77.90 \%$ to $89.6 \%$ with a mean of $85.95 \%$. Conversely, the overall performance for the study group was stronger, with their scores varying from $83.86 \%$ to $92.23 \%$ with a mean of $87.75 \%$. Whereas the range between the low and high scores on the in-class assignments for the control group was $11.70 \%$, this range for the study group was $8.37 \%$. The study group also had higher scores on nine out of the 13 total assessments.

I-strongly disagree to 5-strongly agree) from the survey. Question 17, a double-barrel question, was removed from the analysis.

For the fall semester, the average response was a 4.18 with a low of 3.54 and a high of 4.42 respectively. The highest scores for the fall 2017 semester $(4.42,4.4 I)$ were for three questions measuring understanding - question 5 (the Lightboard videos improved my understanding), and questions I and 4 (the videos were easy to watch and understand, having handwritten notations helped with my understanding). The two lowest scoring questions $(3.54,3.86)$ were for question 6 measuring engagement (interactive nature of the videos made it easier to pay attention and follow) and question 10 measuring satisfaction (I found the videos interesting and stimulating). The highest mean score for fall semester was in the understanding subscale (overall mean 4.32), followed by satisfaction (4.18) and engagement (4.0I).

The average response for the spring 2018 semester (4.2I) was slightly larger than the average response for the fall 2017 semester (4.18). The results were also more concentrated. The range between the lowest scoring question (4.0) and the highest scoring question (4.34) was only 0.34 points. The highest score was recorded for question 14 measuring satisfaction (I would recommend Lightboard videos to my peers). The lowest scores $(4.00,4.01)$ were for two questions measuring engagement - question 6 (interactive nature of the videos made it easier to pay attention and follow) and question 10 (overall, the Lightboard videos were engaging). It is interesting to note the unique change

\begin{tabular}{|c|c|c|c|c|}
\hline \multirow{2}{*}{$\begin{array}{l}\text { Lecture } \\
\text { No. }\end{array}$} & \multirow{2}{*}{ Topics } & \multicolumn{2}{|c|}{ Mean Student Performance } & \multirow[b]{2}{*}{ Assessment Measure } \\
\hline & & Control group & Study group & \\
\hline 2 & Pressure, Barometers, Manometers, Other Pressure Measurement Devices & $86.50 \%$ & $91.11 \%$ & IC Assignments Set \#I \\
\hline 3 & Hydrostatic forces on plane surfaces & $89.01 \%$ & $88.30 \%$ & IC Assignments Set \#2 \\
\hline 4 & Hydrostatic forces on curved surfaces, Buoyancy and Stability & $77.90 \%$ & $88.25 \%$ & IC Assignments Set \#3 \\
\hline 5 & Conservation of Mass, Continuity Equation, Euler and Bernoulli Equations & $86.65 \%$ & $88.60 \%$ & IC Assignments Set \#4 \\
\hline 6 & Reynolds Number, Laminar Flow in Pipes, Turbulent Flow in Pipes, Minor Losses & $84.10 \%$ & $84.32 \%$ & IC Assignments Set \#5 \\
\hline 7 & Energy and Hydraulic Grade lines, Pitot Tubes, Series and Parallel Flows & $88.68 \%$ & $85.50 \%$ & IC Assignments Set \#6 \\
\hline 8 & Dimensional Analysis, Similitude, Orifice \& Venturi Meters & $84.10 \%$ & $83.86 \%$ & IC Assignments Set \#7 \\
\hline 9 & Linear Momentum I & $85.91 \%$ & $86.40 \%$ & IC Assignments Set \#8 \\
\hline 10 & Linear Momentum II, Drag, Lift & $86.30 \%$ & $89.82 \%$ & IC Assignments Set \#9 \\
\hline II & Turbomachinery - Pumps, Pump Performance and System Curves, NPSH & $86.04 \%$ & $84.80 \%$ & IC Assignments Set \#I0 \\
\hline 12 & Pump and Turbine Scaling Laws & $85.20 \%$ & $89.23 \%$ & IC Assignments Set \#II \\
\hline 13 & Principles of Open Channel Flow, Manning's Equation & $87.41 \%$ & $88.30 \%$ & IC Assignments Set \#I2 \\
\hline \multirow[t]{2}{*}{14} & Uniform Flow, Specific Energy, Critical and Normal Depths & $89.60 \%$ & $92.23 \%$ & IC Assignments Set \#I3 \\
\hline & Overall Mean & $85.94 \%$ & $87.73 \%$ & \\
\hline
\end{tabular}

\section{Perception Survey}

Out of the total 68 undergraduate students enrolled in the course during the fall 2017 and spring 2018 semesters, 63 students (92.6\%) of the students completed the perception survey. The sample included I 3 females (20.6\%) and 50 males (79.4\%), which is representative of engineering classes; students were almost equally split on self-reported GPA with 3 I students reporting an overall GPA below 3.0 and 32 students reporting an overall GPA above 3.0.

Data were analyzed using spreadsheets (MS Excel). Table 3 summarizes student responses to 16 Likert-scale questions examining student perceptions of Lightboard videos (a scale from (increase of 3.6\%) in the score for q.6 (engagement) between the fall and spring semesters. In the spring semester, the understanding and satisfaction subscales tied for the overall highest score (4.2I), while the engagement scale had the lowest overall mean score (4.16).

\section{Qualitative Data Analysis}

The last part of the perception survey included five open-ended questions that addressed students' perceptions of the FCM. The following provides a representative sample of the comments received from the questionnaire: 


\begin{tabular}{|c|c|c|}
\hline \multirow{2}{*}{ Questions on Lightboard Videos } & \multicolumn{2}{|c|}{ Mean Student Rating and Ranking } \\
\hline & $\begin{array}{l}\text { Fall } 2017 \\
\mathrm{n}=27\end{array}$ & $\begin{array}{l}\text { Spring } 2018 \\
\mathrm{n}=36\end{array}$ \\
\hline \multicolumn{3}{|l|}{ Understanding } \\
\hline I. The videos were easy to watch and understand. & $4.41(2)$ & $4.21(5)$ \\
\hline 2. The videos helped me visualize the problem solving process. & $4.24(5)$ & $4.14(6)$ \\
\hline 3. The videos helped identify major points in solving each problem. & $4.13(9)$ & $4.28(3)$ \\
\hline 4. Having handwritten notations (equations, etc.) helped with my understanding. & $4.41(2)$ & $4.21(5)$ \\
\hline 5. Overall, the Lightboard videos improved my understanding. & $4.42(1)$ & $4.24(4)$ \\
\hline Subscale Mean & 4.32 & 4.21 \\
\hline \multicolumn{3}{|l|}{ Engagement } \\
\hline 6. The interactive nature of the videos made it easier to pay attention and follow. & $3.54(13)$ & $4.00(10)$ \\
\hline 7. The length of the videos was appropriate. & $4.19(7)$ & $4.14(6)$ \\
\hline 8. Watching the videos was an effective use of my time. & $3.92(11)$ & $4.10(7)$ \\
\hline 9. The Lightboard technology is an appropriate way to engage students through an online environment. & $4.27(4)$ & $4.28(3)$ \\
\hline 10. Overall, the Lightboard videos were engaging. & $4.16(8)$ & $4.31(2)$ \\
\hline Subscale Mean & 4.01 & 4.16 \\
\hline \multicolumn{3}{|l|}{ Satisfaction } \\
\hline II. I found the videos interesting and stimulating. & $3.86(12)$ & $4.01(9)$ \\
\hline 12. The video's technology is attractive (style wise). & $4.08(10)$ & $4.07(8)$ \\
\hline 13. The videos are an effective tool for learning about fluid mechanics. & $4.24(5)$ & $4.24(4)$ \\
\hline 14. I would recommend Lightboard videos to my peers. & $4.34(3)$ & $4.34(1)$ \\
\hline I5. I would recommend developing and using more Lightboard videos for this class. & $4.23(6)$ & $4.28(3)$ \\
\hline 16. I would recommend developing and using more Lightboard videos for other engineering courses. & $4.34(3)$ & $4.31(2)$ \\
\hline Subscale Mean & 4.18 & 4.21 \\
\hline
\end{tabular}

What did you like most about the "flipped classroom" approach used for this course?

- I liked that we did our homework in class because that is what most students struggle with and seldom seek help with.

- I liked have exposure to the material multiple times: at home, at the beginning of each class, and during the problem solving sessions.

- It forced students to work together as a group (something we will have to do when we graduate).

- Having daily tickets and in-class assignments helped me keep up in the class and not fall behind.

- It allowed me to study and learn at my own pace.

Was there anything about the "flipped classroom" that you did not like?

- It required me to retrain myself (during the first few weeks) because it was so different.

- If somebody within the group was not pulling their weight, it put extra work on the other group members.

- I didn't like having to learn the material from scratch by myself.

- l'd like to see more intervention by the instructor during the in-class problem solving sessions. He made the group work through our own difficulties which was frustrating.

- I felt that the online lessons had less examples.
If you could offer one suggestion to improve the inverted learning experience, what would it be?

- I'd like to see some more cool videos.

- Sometimes the color of the instructor's shirt interfered with the writing on the Lightboard. He needs to choose his shirt color wisely.

- I'd like to see more in-class examples so that I can hear the teacher's explanations.

- Assign additional (independent) homework problems for students to do outside of class.

- Highlight key points in the videos and lessons.

In what ways has the "flipped classroom" learning environment helped you learn this semester?

- It's really beneficial having the teacher available in class to answer my homework-related questions.

- I found it helpful to review the material at home then come to class with specific questions.

- It helped me with attendance since it was important to come to class.

- I learned a lot by working with others.

- It takes the focus away from doing homework for just the grade. 
In what ways did the "flipped classroom" learning environment not help you to learn this semester?

- Since the in-class activities focused on problem-solving, I felt like I didn't learn enough about the theory.

- The tickets focused on mostly concepts, while the homework focused on calculations. It wasn't always clear which part (concepts, application) was more essential in the class.

- Having in-class homework kept me from studying more outside the classroom.

- $\quad$ Sometimes (not often) I piggybacked off other students and didn't contribute to the problem solving sessions.

- I learn better in a lecture-based classroom environment.

\section{DISCUSSION}

Given the paucity of research studies evaluating the effect of Lightboard videos on student learning, this study provides a needed initial exploration by investigating both student learning as exemplified by performance on in-class assignments and student perceptions. The study sought to explore the following questions:

\section{Are there differences in students' academ- ic performance between a FCM using Light- board videos and a FCM not using Lightboard videos (as measured by the average grades on in-class assignments)?}

The overall trend is promising and seems to show a modest academic performance increase ( $1.79 \%)$ on the overall score on in-class assignments and an improvement of average student scores on $69.2 \%$ of the in-class assignments in the study group. While it appears that having access to the Lightboard videos may contribute to student learning, the variability of the in-class assignment-level data (Table 2) and modest overall increases do not seem to support an increase in academic performance with absolute certainty. While previous research indicated no improvement in performance indicators for circuit problem skills, it did improve certain components of learning such as diagrams and sketches, neatness, organization (Hite et al, 20I7). Several other publications on Lightboard did not evaluate student performance at all. Given the lack of adequate research assessing the effect of Lightboard videos on student learning, future research projects should target larger samples and use multiple sources of performance indicators to examine whether Lightboard videos increase student learning.

\section{What are student perceptions of under- standing, engagement and satisfaction with Lightboard videos in a FCM?}

The quantitative (Likert-scale questions) data collected through the end-of-semester student perception survey provided valuable insight regarding the use of Lightboard videos. The overall means for all subscales are above a 4.0 on a 5.0 point scale, which showed a strong endorsement of Lightboard videos for understanding, engagement and satisfaction. It is particularly encouraging that the understanding subscale scored highest in the fall semester (subscale mean 4.32) with three of the subscale items ranking as top three of all items on the survey. Students had a strong agreement that the Lightboard videos improved their understanding. While the academic performance data do not seem to unequivocally support this, some of our previous studies reported on such dichotomy between learning and perceptions (Sturges et al., 2009).
It seems that students often think they learn and understand the material, but in reality they do not. It is possible that the assessment measures did not capture the whole story, as grades are often the most readily available measures of performance, but not necessarily the best indication of learning. Future studies should consider using multiple measures of academic performance for a better understanding of pedagogical innovations on learning.

It is curious that in the spring semester, the understanding subscale decreased in importance (subscale mean 4.2I). It is possible that this decrease in overall mean for the understanding scale is related to student characteristics - often spring semesters have students who are repeating a class. However, it still tied with the satisfaction subscale, which also held the three top ranking items. It appears that students like the Lightboard videos, would like to see more of them in engineering classes and would recommend them to their peers. This view stayed consistent from one semester to another and was true of the engagement component, as well. Lower student ratings on the engagement subscale (the interactive nature of the videos made it easier to pay attention and follow, is an appropriate way to engage students through an online environment., etc.) clearly indicate that there is a more passive component to the videos and perhaps most of the engagement should be expected in the face-to-face meetings.

\section{What are student perceptions about the FCM?}

The qualitative (short answer questions) data collected through the end-of-semester survey provided valuable insight regarding student perspectives of flipped classrooms. Students benefitted from having exposure to the lesson material multiple times: online before class, during the instructor's lesson review at the beginning of class, and during the in-class problem solving sessions. It also allowed students to review the material at their own pace. This is perhaps one of the biggest advantages for the model: it can accommodate students who like the freedom to move quickly through the material, while offering an opportunity to move at a slower pace and replay notes, take notes, etc. for students who struggle with certain topics. At the same time, a new format can be challenging to students. They have to learn new technologies and/or develop a more independent way to study for the class, which can increase resistance to a new format of delivery. This is reported in other literature, as well (Wilson, 2013). It is curious though, that these comments did not extend to Lightboard videos, as evidenced by high scores on the Likert scale. It seems that students would prefer more of face-to-face interaction and the videos as supplement to the lectures. The FCM allowed the instructor to use class time for more challenging and engaging activities, where tickets tested "concepts" and in-class assignments explored practical applications by focusing on calculations. Students also commented positively on the collaborative aspect of in-class problem solving, another finding supporting previous literature (Strayer, 2007).

\section{Limitations}

The study was mostly exploratory in nature, given limited previous research data on the effects of the Lightboard on student learning. The relatively small size of the sample in the study and the focus on engineering students only, prevents us from generalizing the results.Although we used data from two semesters and had a high response rate to the perception survey, future studies 
should investigate Lightboard video use in large classes or over the course of multiple semesters.

Ideally, having one class as a control group and another as study group may give researchers more control over study variables. We chose to alternate the Lightboard videos every other class in each semester due to the potential of contamination. The civil engineering program is rather small and student interaction is expected.At this point, our data seem to indicate that students enjoy the Lightboard videos and perceive an increase in understanding, engagement and satisfaction, so withholding videos from an entire section may be unethical. Finally, it seems that the videos contributed positively to student learning, but not significantly. Future studies should consider collecting additional measures of academic performance, such as test grades in addition to in-class assignments, to better evaluate the effect on learning.

\section{Implications for future classes}

Our research and personal experience with Lightboard indicate the value of this technology for student learning. We plan to continue creating and using Lightboard videos in our future classes. Although not included in the results of this study, our student evaluations show that most students have a high preference for the Lightboard videos and are asking us to create additional ones. It is our observation that changes can be made based on the type of content presented in the video and perhaps the subject taught. For example, in our human anatomy and physiology classes, additional guided questions were created to accompany most Lightboard videos. This is possible because in anatomy, understanding structures and being able to label them on their own (before and/or after watching the video), reinforces the content included in the videos. Although sometimes, we, as instructors, are often cautious about trying a new technology, we found Lightboard to be very user friendly, easy to learn and rewarding to provide as an additional resource to students. Having the support of a teaching center in creating and editing the videos, as well as planning and preparing in advance to record them, makes the process more efficient and less time consuming.

\section{ACKNOWLEDGEMENT}

The Lightboard videos used for this project were developed through a collaborative effort between the University's Center for Online Learning (COL), Information Technology Services (ITS), Multimedia Development Center and the Department of Civil Engineering and Construction Management. Whereas the videos were recorded by the first author at the MDC with help from MDC staff, COL staff assisted with the pre-recording training and final video editing and publishing. The Lightboard unit was constructed by Jessica and Jeff Orvis, faculty members in the Chemistry Department at our University. This project was made possible through the SoTL Fellowship program sponsored by the university's Center for Excellence in Teaching.

\section{REFERENCES}

Baepler, P., Walker, J.D., \& Driessen, M. (20I4). It's not about seat time: Blending, flipping, and efficiency in active learning classrooms. Computers and Education, 78, 227-236.

Bishop, J.L., \& Verleger, M.A. (20I3, June 24). Flipped classroom:A survey of the research. Paper presented at the 2013 ASEE Annual Conference \& Exposition. Retrieved from https:// www.asee.org/public/conferences/20/papers/6219/view
Chen, Y., Wang,Y., \& Chen, N.S. (20I4). Is Flip enough? Or should we use the Flipped model instead? Computers \& Education, 79, 16-27.

Davies, R.S., Dean, D.L., \& Ball, N. (2013). "Flipping the classroom and instructional technology integration in a college-level information systems spreadsheet course," Educational Technology Research and Development (ETR\&D), 6I (4), 563-580.

Day, J., \& Foley, J.D. (2006). Evaluating a web lecture intervention in a human-computer interaction course. IEEE Transactions on Education, 49(4), 420-43I.

Fitzgerald N., \& Li, L. (20I5). Using presentation software to flip and undergraduate analytical chemistry course. Journal of Chemical Education, 92, I559-I563.

Frederickson, N., Reed, P., \& Clifford,V. (2005). Evaluating web-supported learning versus lecture-based teaching: Quantitative and qualitative perspectives. Higher Education, 50, 645-664.

Fung, Fun Man (2017). Adopting Lightboard for a Chemistry Flipped Classroom To Improve Technology-EnhancedVideos for Better Learner Engagement. Journal of Chemical Education, 94 (7), 956-959.

Gerstein, J. (2012). Flipped classroom:The full picture for higher education. Retrieved from https://usergeneratededucation. wordpress.com/20 I 2/05/ I5/flipped-classroom-the-full-picture-for-higher-education/.

Goodwin, B., \& Miller, K. (20I3). Evidence on Flipped Classrooms is Still Coming In. Educational Leadership, 70(6), 78-80.

Halyo, N. \& Le, Q. (20I3, June). Use of Video Technology to Improve Student Learning. Paper presented at the 2013 ASEE Annual Conference \& Exposition, https://peer.asee. org/22686

Hite, K.R., Dawson, J.M., Ahern, T.C., Slimak, L.L., \& Korakasis, D. (2017). Effects of lightboard usage on circuit problem skills. Paper presented at the IEEE Frontiers in Education Conference, https://ieeexplore.ieee.org/document/8190529

Itani, M. (20I3). The effectiveness of videos as a learning tool in an engineering ethics course:A students' perspective. Paper presented at the 2013 ASEE Annual Conference \& Exposition, https://peer.asee.org/22578

Johnson, L.W., \& Renner, J.D. (20I2). Effect of the flipped classroom model on a secondary computer applications course: Student and teacher perceptions, questions, and student achievement (Doctoral Dissertation), Retrieved from: https://theflippedclassroom.files.wordpress.com/20 I2/04/ johnson-renner-20I2.pdf.

Kao, I. (2008). Using Video Podcast to Enhance Students' Learning Experience in Engineering. Paper presented at the 2008 Annual ASEE Conference \& Exposition, https://www.asee. org/documents/sections/middle-atlantic/spring-2008/02-Using-Video-Podcast-to-Enhance-Students-Learning-Experience-in-Engineering.pdf

Kim, M.K., Kim, S. M., Khera, O., \& Getman, J. (20I4). The experience of three flipped classrooms in an urban university: An exploration of design principles. The Internet and Higher Education, 22, 37-50.

Lage, M.J., Platt, G.J., \& Treglia, M. (2000). Inverting the classroom: A gateway to creating an inclusive learning environment. The Journal of Economic Education, 31, 30-43.

Lucas, B., \& Hanson, J. (2016) Thinking Like an Engineer: Using Engineering Habits of Mind and Signature Pedagogies to Redesign Engineering Education. International Journal of Engi- 
neering Pedagogy, 6 (2), 4- 13.

McLaughlin, J.C., Roth, M.T., Glatt, D.M., Gharkholonarehu, N., Davidson, C.A., Griffin, L.M., \& Mumper, R. J. (20I4). The flipped classroom: A course redesign to foster learning and engagement in a health professions school. Academic Medicine, 89, I-8.

Missildine, K., Fountain, R., Summers, L., \& Gosselin, K. (20|3). Flipping the classroom to improve student performance and satisfaction. Journal of Nursing Education, 52(10), 597-599.

Moravec, M., Williams, N., Aguilar-Roca, N., \& O’Dowd, D.K. (2010). Learn before lecture:A strategy that improves learning outcomes in a large introductory biology class. CBE-Life Sciences Education, 9(4), 473-48I.

Shulman, L.S., (2005). Signature pedagogies in the professions, Daedalus, 134 (3), 52-59.

Smith, T., \& Penumetcha, M. (2017). Lightboard, Camera, Nutrition! Journal of the Academy of Nutrition and Dietetics, I I 7(9): A-70.

Strayer, J. (2007). The effects of the classroom flip on the learning environment: $A$ comparison of learning activity in a traditional classroom and a flip classroom that used an intelligent tutoring system. (Doctoral Dissertation), Retrieved from http://faculty.washington.edu/rvanderp/DLData/FlippingClassDis.pdf
Sturges, D., Maurer, T.W., \& Cole, O. (2009). “Understanding Protein Synthesis: A Role Play Approach in Large Undergraduate Human Anatomy and Physiology Classes". Advances in Physiology Education, 33, I03-I I0.

Tucker, B. (20I2). The flipped classroom. Education Next, I2(I), 8283.

Tune, J.D., Sturek, M., \& Basile, D. (20I3). Flipped classroom model improves graduate student performance in cardiovascular, respiratory and renal physiology. Advances in Physiology Education, 37, 316-320.

Wilson, S.G. (20I3). The flipped class: A method to address the challenges of an undergraduate statistics course. Teaching of Psychology, 40(3), 193-199.

Zappe, S., Leicht, R., Messner, J., Litzinger, T., \& Lee, H.W. (2009). Flipping the classroom to explore active learning in a large undergraduate course. Paper presented at the 2009 ASEE Annual Conference \& Exhibition, http://www.researchgate.net/publication/26020 I I I9_Flipping_the_classroom to_explore_active_learning_in_a_large_undergraduate_ course. 


\section{APPENDIX A}

\section{CENG 2 I 3 I: End-of-Semester Survey}

The following questions relate to the instructor's use of the" flipped classroom" approach and Lightboard videos for this course and will only be used in understanding your perceptions and opinions of the teaching method. The instructor appreciates your honesty in answering the questions and assures you that your answers will not have any impact on your course grade. Please do not write your name anywhere on this sheet.

\section{General Information}

I. Please indicate your gender:
a. Male
b. Female

2. Please indicate your overall grade point average within the following ranges:
a. $<2.0$
b. $2.1-2.5$
c. $2.6-3.0$
d. $3.1-3.5$
e. $>3.5$

\section{Part 1: Questions pertaining to the Flipped Classroom}

3.What did you like most about the "flipped classroom" approach used for this course?

4.Was there anything about the "flipped classroom" that you did not like?

5. If you could offer one suggestion to improve the flipped learning experience, what would it be?

6. It what ways has the "flipped classroom" learning environment helped you learn this semester?

7. It what ways did the "flipped classroom" learning environment not help you to learn this semester? 
Part 2: Questions pertaining to the Lightboard Videos

Please use the table below in rating different aspects of the course's LightboardVideos. Use the following scale for your evaluation: $\mathrm{I}=$ strongly disagree

2 = disagree

$3=$ neither agree or disagree

$4=$ agree

$5=$ strongly agree

\begin{tabular}{|c|c|c|c|c|c|}
\hline & I & 2 & 3 & 4 & 5 \\
\hline \multicolumn{6}{|l|}{ Understanding } \\
\hline I.The videos were easy to watch and understand. & $\square$ & $\square$ & $\square$ & $\square$ & $\square$ \\
\hline 2. The videos helped me visualize the problem solving process. & $\square$ & $\square$ & $\square$ & $\square$ & $\square$ \\
\hline 3. The videos helped identify major points in solving each problem. & $\square$ & $\square$ & $\square$ & $\square$ & $\square$ \\
\hline 4. Having handwritten notations (equations, etc.) helped with my understanding. & $\square$ & $\square$ & $\square$ & $\square$ & $\square$ \\
\hline 5. Overall, the Lightboard videos improved my understanding. & $\square$ & $\square$ & $\square$ & $\square$ & $\square$ \\
\hline \multicolumn{6}{|l|}{ Engagement } \\
\hline 6. The interactive nature of the videos made it easier to pay attention and follow. & $\square$ & $\square$ & $\square$ & $\square$ & $\square$ \\
\hline 7. The length of the videos was appropriate. & $\square$ & $\square$ & $\square$ & $\square$ & $\square$ \\
\hline 8. Watching the videos was an effective use of my time. & $\square$ & $\square$ & $\square$ & $\square$ & $\square$ \\
\hline 9. The Lightboard technology is an appropriate way to engage students through an online environment. & $\square$ & $\square$ & $\square$ & $\square$ & $\square$ \\
\hline 10. Overall, the Lightboard videos were engaging. & $\square$ & $\square$ & $\square$ & $\square$ & $\square$ \\
\hline \multicolumn{6}{|l|}{ Satisfaction } \\
\hline II.I found the videos interesting and stimulating. & $\square$ & $\square$ & $\square$ & $\square$ & $\square$ \\
\hline 12. The video's technology is attractive (style wise). & $\square$ & $\square$ & $\square$ & $\square$ & $\square$ \\
\hline 13. The videos are an effective tool for learning about fluid mechanics. & $\square$ & $\square$ & $\square$ & $\square$ & $\square$ \\
\hline I4. I would recommend Lightboard videos to my peers. & $\square$ & $\square$ & $\square$ & $\square$ & $\square$ \\
\hline I5. I would recommend developing and using more Lightboard videos for this class. & $\square$ & $\square$ & $\square$ & $\square$ & $\square$ \\
\hline 16. I would recommend developing and using more Lightboard videos for other engineering courses. & $\square$ & $\square$ & $\square$ & $\square$ & $\square$ \\
\hline I7.Overall, I enjoyed and recommend the Lightboard videos. & $\square$ & $\square$ & $\square$ & $\square$ & $\square$ \\
\hline
\end{tabular}

